\title{
Perancangan Aplikasi Galeri E-Jurnal Dengan REST API Berbasis Android
}

\author{
Design Application E-Journal Gallery With Android-Based Representational State Transfer Application \\ Programming Interface \\ Fira Sri Handayani' ${ }^{1,}$ Rika Rosnelly ${ }^{2 *}$ \\ 1,2*Program studi Informatika Fakultas Teknik dan Informatika Universitas Potensi \\ Utama \\ E-mail : ${ }^{1}$ firahandayani30@gmail.com, $2{ }^{2 *}$ rikarosnelly@gmail.com \\ *Corresponding author
}

\begin{abstract}
Abstrak
Sistem pencarian jurnal masih dilakukan secara bertahap dengan menggunakan web browsing. Sistem pencarian bertahap ini memiliki beberapa kelemahan, antara lain proses pencarian jurnal yang lambat dan kurang efisien. Dari permasalahan diatas maka penulis mengusulkan untuk merancang dan membangun suatu sistem untuk melaksanakan pencarian jurnal dengan memanfaatkan teknologi informasi yang disebut aplikasi jurnal elektronik atau istilah sekarang bernama e-journal menggunakan rest api diaplikasikan melalui smartphone android yang dirancang dengan sangat sederhana dan biaya yang relatif murah sehingga memudahkan para pengguna. Penggunaan teknologi smartphone android saat ini banyak dipakai untuk ketersediaan transaksi elektronik, karena kecepatan, keamanan dan ketepatan data yang dihasilkan.Aplikasi jurnal elektronik menggunakan teknologi berbasis android dirancang dengan sangat sederhana sehingga memudahkan para pengguna agar dapat dijadikan sebagai media alternatif untuk pencarian jurnal secara elektronik.
\end{abstract}

Kata Kunci- E- Jurnal, Rest API, Android.

\begin{abstract}
Journal search system is still done using web search. This phased search system has several weaknesses, including a fast and inefficient journal search process. From the discussion above, the authors publish to compile and compile a system for conducting research in journals using information technology called electronic journal applications or the term now called e-journal using the Representational State Transfer Aplication Programming Interface applied through an Andorid smartphone that is designed easily and cheaply which is adjusted to make it easier for users. The use of android smartphone technology is currently widely used for electronic transactions, because of the speed, security and accuracy of the data generated. The application of electronic journals using Android-based technology is designed with great ease for users to be used as an alternative medium for finding journals that use electronics.
\end{abstract}

Keywords - e-Journal, Representational State Transfer Application Programing Interface, Android

\section{PENDAHULUAN}

E-Jurnal merupakan media teknologi informasi yang memiliki kemampuan untuk mengembangkan aplikasi pembelajaran. Kegiatan yang diakses dilakukan untuk menentukan jalan keluar yang dianggap paling baik dalam menyelesaikan referensi tugas pada mahasiswa. Namun kegiatan pencarian jurnal sering pula dilakukan dalam skala yang lebih kecil contohnya sebagai referensi. Pencarian jurnal biasanya dilakukan untuk memenuhi tugas daripada mahasiswa.Namun pada umumnya mengakses untuk pencarian jurnal mempunyai tahap-tahap yaitu dengan searching ke google terlebih dahulu kemudian menggunakan web browser kemudian akan keluarkan beberapa jurnal yang dicari. Proses yang lambat karena proses pencarian masih dilakukan secara bertahap, kurang akuratnya proses pencarian jurnal ketika mengakses pencarian jurnal.Dengan 
melihat masalah yang ada, untuk itu penulis ingin mencoba merancang dan membangun suatu aplikasi Elektronik jurnal atau lebih familiar disebut dengan E-jurnal yang dapat berjalan pada sistem Rest API yang akan diterapkan pada perangkat Smartphone berbasis Android sebagai aplikasi Web dan sebagai aplikasi admin atau server-nya.

Sebuah penelitian yang telah dilakukan sebelumnya, dapat diberi kesimpulan bahwa penelitian ini menghasilkan sebuah aplikasi pengembangan media pembelajaran matematika berbasis android untuk siswa SD/MI aplikasi ini melibatkan pakar pada proses pengembangan dan penilaian produknya. Metode: Penelitian ini merupakan penelitian pengembangan (Research and Development). Prosedur pengembangan menggunakan model 4D, yaitu: define (analisis pengguna, kurikulum, dan bahan ajar), design (merancang produk dengan alat dan bahan), develop (penilaian dan revisi), dan disseminate (uji coba pada calon pengguna). Instrumen penelitian ini adalah angket [1].

Penelitian dengan menghasilkan sebuah aplikasi pengembangan mobile learning berbasis android sebagai sarana berlatih mengerjakan soal matematika yang bertujuan untuk mengembangkan mobile learning yang berupa game quiz berbasis android pada materi barisan dan deret [2].

Pada penelitian yang dilakukan menyatakan bahwa penelitian ini menghasilkan aplikasi perancangan sistem informasi mobile berbasis android untuk kontrol persediaan barang di gudang dimana pada Sistem informasi gudang yang telah dirancang ini menyimpan seluruh transaksi penerimaan dan pengiriman barang sehingga pihak perusahaan dapat memantau pengeluaran dan penerimaan serta persediaan barang di perusahaan [3].

Penelitian yang menghasilkan aplikasi mobile driver online berbasis android untuk perusahaan rental kendaraan Perangkat lunak aplikasi mobile driver online pada platform android sudah membantu pelanggan melakukan pemesanan mobil dan memesan driver yang sesuai dengan pilihannya serta aplikasi mobile driver online pada platform android sudah membantu driver untuk mendapatkan order [4].

Penelitian ini merupakan aplikasi panduan kepaskibraan berbasis android, aplikasi ini dapat disimpulkan aplikasi panduan kepaskibraan dengan digunakannya REST API dalam pembuatan Aplikasi Panduan Kepaskibraan dan dengan adanya dukungan notasi JSON maka memudahkan dalam proses penerapan teknologi pada aplikasi yang dibangun. Diawali dengan membangun web service, REST yang terbukti handal. Membuat beberapa controller yang diperlukan untuk akses aplikasi pada perangkat android maupun pengelolaan konten pada web admin [5].

Pada penelitian yang dilakukan sebelumnya, menghasilkan aplikasi deteksi gempa secara realtime berbasis android di indonesia, dalam aplikasi ini terdapat berbagai informasi seperti informasi cuaca, iklim, kualitas udara serta informasi mengenai gempa terkini. Aplikasi ini juga memberikan informasi mengenai jarak antara pengguna dan pusat gempa dengan memanfaatkan GPS [6].

Menurut penelitian sebelumnya yang dilakukan, dapat diberi kesimpulan bahwa Web service dapat digambarkan sebagai sebuah sistem yang dirancang untuk dapat mendukung interaksi komunikasi antar mesin-mesin pada suatu jaringan, pada aplikasi perpustakaan berbasis android dengan memanfaatkan web service rest [7].

Penelitian [8] melakukan rancang bangun layanan web (web service) untuk aplikasi rekam medis praktik pribadi dokter dengan Layanan web sudah dapat memenuhi kebutuhan pada aplikasi rekam medis praktik pribadi dokter, yaitu sudah dapat mengakses datastore yang tersimpan Google App Engine (GAE).

Penelitian [9] berdasarkan tujuan penelitian ini adalah merancang web service pada sistem informasi sekolah yang sesuai dengan Standar Nasional Pendidikan (SNP) menggunakan arsitektur web service REST. Hasil pengembangan rancangan web service sistem informasi yaitu dengan memetakan class diagram yang akan dibuat pada perancangan web service sekolah dengan menambahkan modul modul pada JIBAS yang mengacu pada Peraturan Menteri Pendidikan Nasional yang sesuai dengan 8 standar BSNP [9]. Penelitian [10] melakukan implementasi pada sisi server maupun sisi client dilakukan setelah melalui proses analisis dan perencanaan. Pada sisi server, dikembangkan sistem web service yang berfungsi untuk menyediakan data atau resources pada client. Pada sisi client dikembangkan aplikasi desktop yang akan dipasang di ruangan kelas untuk menampilkan QR Code dan aplikasi mobile yang akan dipakai dua jenis user yaitu dosen dan mahasiswa.

Penelitian [11] merancang aplikasi rekrutmen asisten laboratorium fakultas teknik dengan Proses yang dimulai dari tahapan pengiriman berkas, memiliki hambatan jarak bagi peserta karena harus mengirimkan langsung ke laboratorium. Serta penyebaran informasi mengenai jadwal pelaksanaan tes serta 
pengumuman hasil seleksi yang dirasa masih kurang efektif menjadi alasan paling mendasar dalam pembangunan aplikasi ini. Aplikasi ini dibangun dengan menggunakan tahapan perancangan perangkat lunak Prototype. Dengan menggunakan dua platform yang berbeda yaitu Mobile dan web. Penggunaan REST API menjadi cara agar data yang berada di dalam satu Database yang sama dapat diakses dengan baik pada platform yang berbeda.

Penelitian [12] peningkatan sistem seleksi ujian sharing masuk dengan metode Linear Congruent Method (LCM). Metode Linear Congruent Method adalah salah satu metode yang mampu melakukan pembangkitkan bilangan acak pada sebuah program. Metode ini digunakan untuk mengacak soal yang ada sehingga tersusunlah soal-soal tersebut secara random dan siap untuk diberikan kepada calon mahasiswa [12].

Penelitian [13] merancang aplikasi ini alat stempel otomatis lembar jawaban STMIK potensi utama dengan menggunakan 1 buah motor servo sebagai motor penggerak stempel dengan torsi mencapai $4 \mathrm{~kg}$ dan 1 buah motor DC sebagai penggerak roda-roda pembuka lipatan kertas.

Penelitian [14] menghasilkan aplikasi pemesanan dan penjualan web dan android pada toko YT. Wall interior dalam penelitian ini untuk mendukung terwujudnya sebuah aplikasi yang mampu mengembangkan usaha pada Toko YT. Wall Interior peneliti membuat aplikasi berbasis web dan android yang nantinya akan berisi fitur-fitur semacam jenis wallpaper yang ditawarkan, berapa stok barang yang ditoko, dan cara pemesanannya.

\section{METODE PENELITIAN}

Perancangan aplikasi mobile e-journal memiliki tahapan - tahapan. Adapun tahapan tersebut dapat dilihat pada Gambar 1.

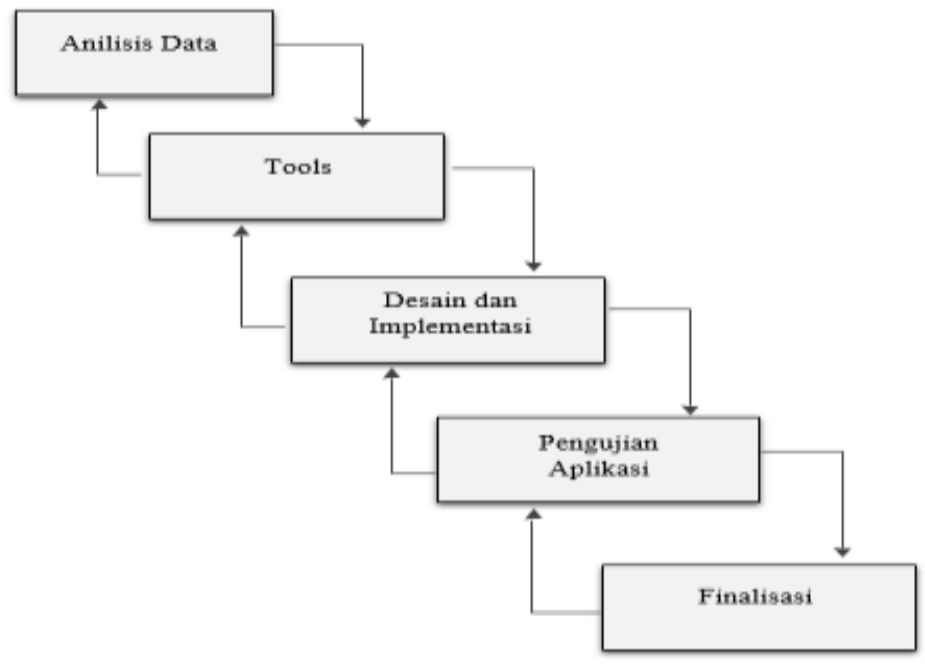

Gambar 1. Alur Perancangan Aplikasi Galeri E-Jurnal Dengan REST API Berbasis Android

1. Analisis Data

Analisis data yaitu hal-hal yang diperlukan berupa pengumpulan data atau informasi terkait prosedur kerja galeri e-jurnal dan coding pemrograman beserta tahap pengujian yang digunakan untuk menemukan informasi yang bermanfaat sehingga dapat memberikan petunjuk yang dibutuhkan untuk membangun aplikasi.

2. Tools

Pada tahap ini spesifikasi perangkat keras dan perangkat lunak (software) yang digunakan sesuai perencanaan yaitu :

A. Perangkat Keras (Hardware)

- Laptop

- Hard Disk : $500 \mathrm{~GB}$

- RAM 4 GB 
B. Perangakat Lunak (Software)

- Sistem operasi windows 10

- Android Studio

- Text Editor (Sublime Text)

- XAMPP

3. Desain dan Implementasi

Pada tahap ini dirancang sebuah desain sistem antarmuka dari aplikasi e-jurnal berbasis android dengan memanfaatkan pemodelan UML (Unified Modeling Language), dan kemudian akan di implementasikan dalam bentuk aplikasi. Alat bantu yang digunakan dalam perancangan berorientasi objek berbasiskan UML adalah sebagai berikut: use case diagram, activity diagram, sequence diagram

4. Pengujian Aplikasi

Pengujian aplikasi dilakukan untuk menjalankan sebuah aplikasi yang di uji dapat berjalan sesuai dengan yang direncanakan dalam perancangan yang akan digunakan dalam pembuatan aplikasi. Lalu desain yang dirancang dapat di implementasikan kedalam bahasa pemrograman.

5. Finalisasi

Pada tahap ini akan diambil kesimpulan dari perancangan aplikasi e-jurnal berbasis android yang telah dihasilkan, seperti apa saja kelebihan dan kekurangan dari aplikasi tersebut. Sehingga didapatkan kesimpulan untuk menambahkan fungsi-fungsi tertentu sesuai dengan kebutuhan ke dalam aplikasi.

\section{HASIL DAN PEMBAHASAN}

Berikut dalam penyusunan suatu program diperlukan suatu model data yang berbentuk diagram yang dapat menjelaskan suatu alur proses sistem yang akan di bangun. Dalam penelitian ini penulis menggunakan metode UML yang dalam metode itu penulis menerapkan diagram Use Case. Berikut Use Case Diagram Perancangan Aplikasi Informasi tentang galeri e-jurnal berbasis android yang dapat dilihat pada Gambar 2.

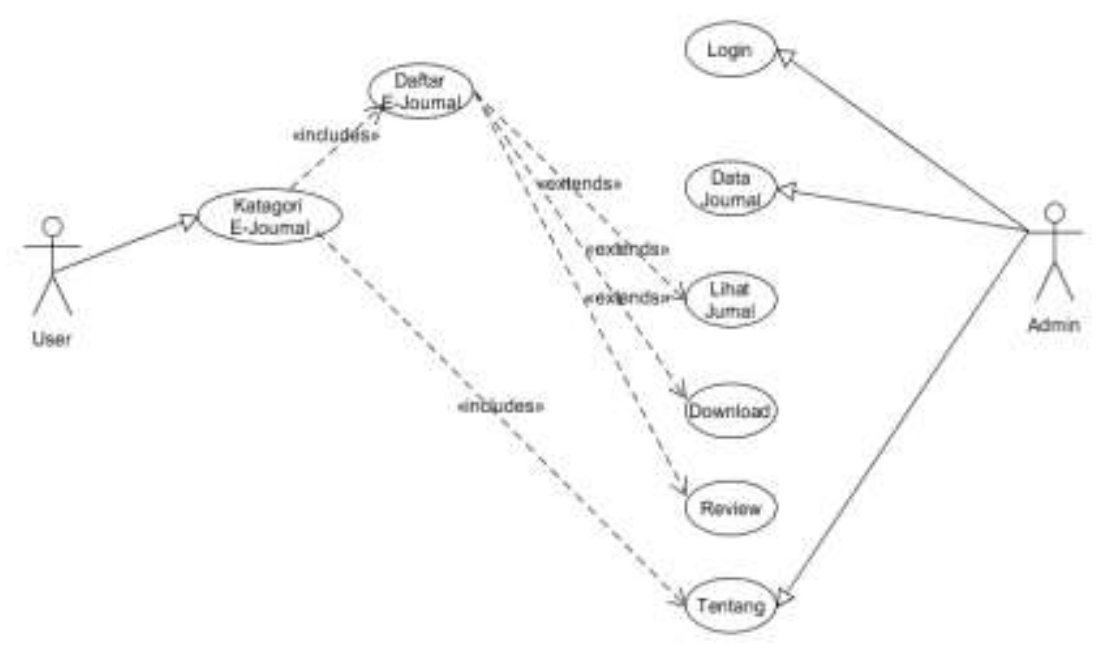

Gambar 2. Use Case Diagram Perancangan Aplikasi Galeri E-Jurnal Dengan REST API Berbasis Android 


\subsection{Tampilan Pada Web Admin}

1. Tampilan Halaman Login Web

Tampilan login akan tampil saat pertama kali user menjalankan sistem. Halaman login digunakan untuk memberikan layanan keamanan dengan memasukkan username dan password. dapat dilihat Gambar 3.

(1) Not secure f firahandayani.000 webhostapp.com/jurnal/index php?aksi=juma

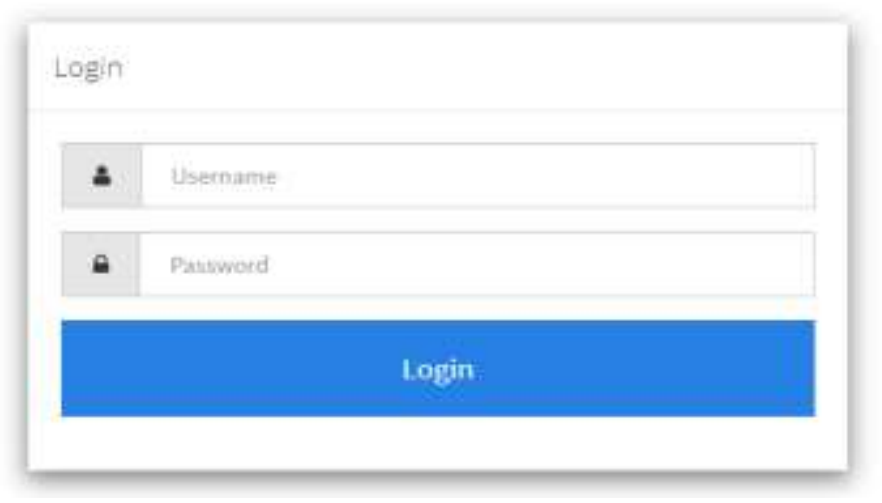

Gambar 3. Halaman web admin

2. Tampilan Halaman Beranda Web Admin

Halaman beranda, merupakan sebuah halaman untuk menampilkan fitur tombol home, user, kategori, jurnal yang terdapat dalam database. Untuk lebih jelasnya tampilan halaman home pada aplikasi e-jurnal pencarian jurnal berbasis android dapat dilihat pada Gambar 4. dapat dilihat pada Gambar 4.

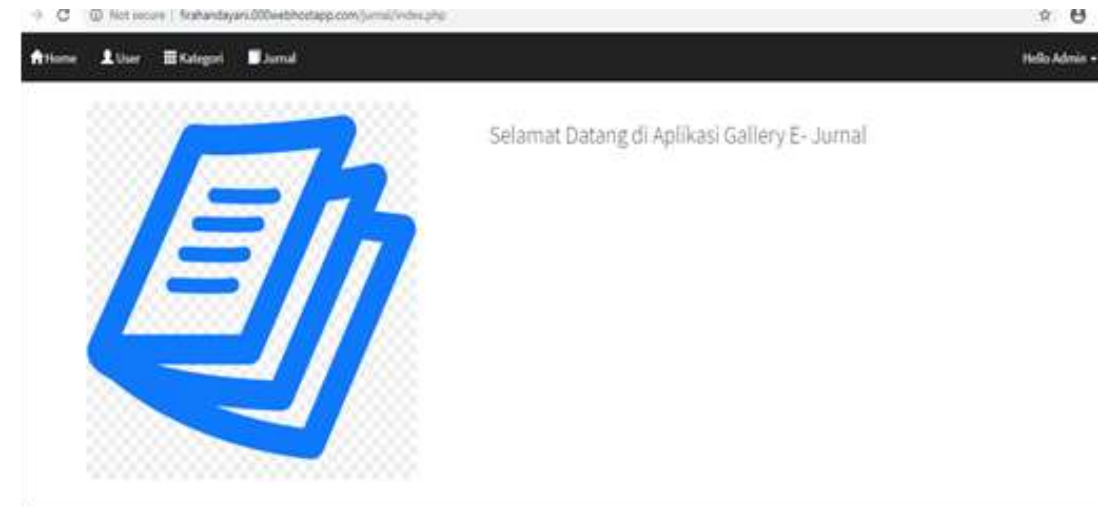

Gambar 4. Halaman beranda admin

\section{Tampilan Halaman Kategori}

Pada halaman kategori merupakan tampilan untuk memberikan informasi data kategori. Berikut merupakan gambar tampilan halaman kategori pada aplikasi e-jurnal pencarian sebuah jurnal berbasis android yang dapat dilihat pada Gambar 5 . 


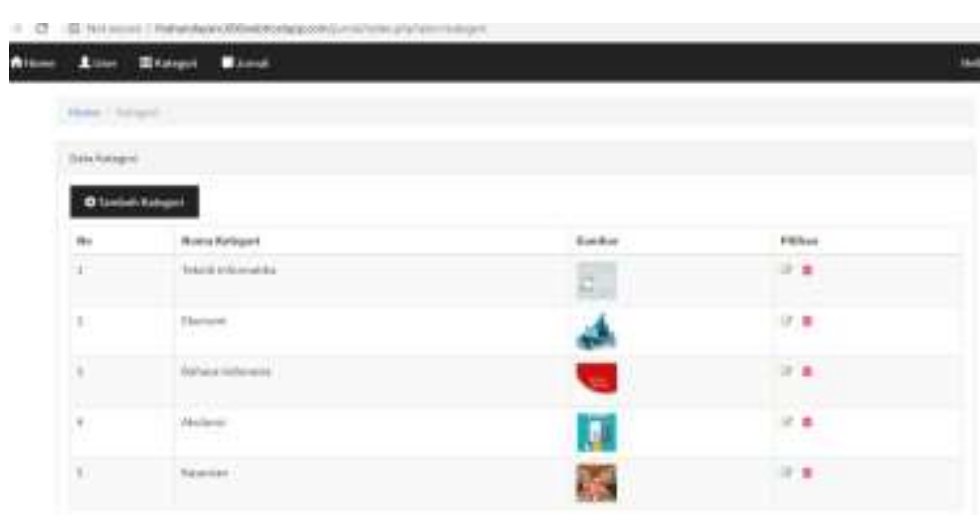

Gambar 5. Tampilan Halaman Kategori

\subsection{Tampilan Pada Aplikasi Splash Screen}

1. Halaman Aplikasi Splash Screen

Halaman Splash Screen Halaman ini menampilkan pertama program yang muncul sementara sebelum masuk ke menu utama. Gambar tampilan halaman splash screen ditunjukkan pada Gambar 6.

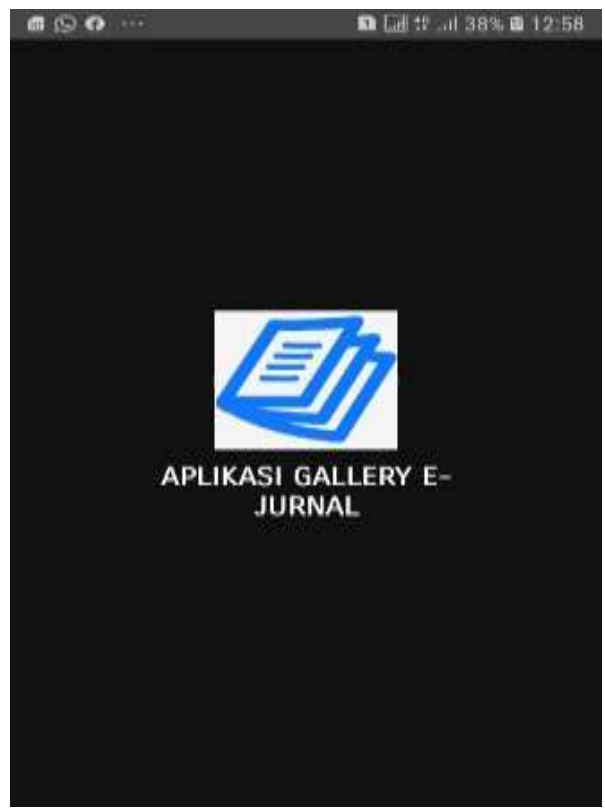

Gambar 6. Halaman Splash Screen

2. Halaman Aplikasi Kategori Jurnal

Pada halaman ini ditampilkan kategori jurnal. Setelah dipilih akan menampilkan detail terkait daftar jurnal. Gambar tampilan halaman kategori jurnal dapat dilihat pada Gambar 7. 


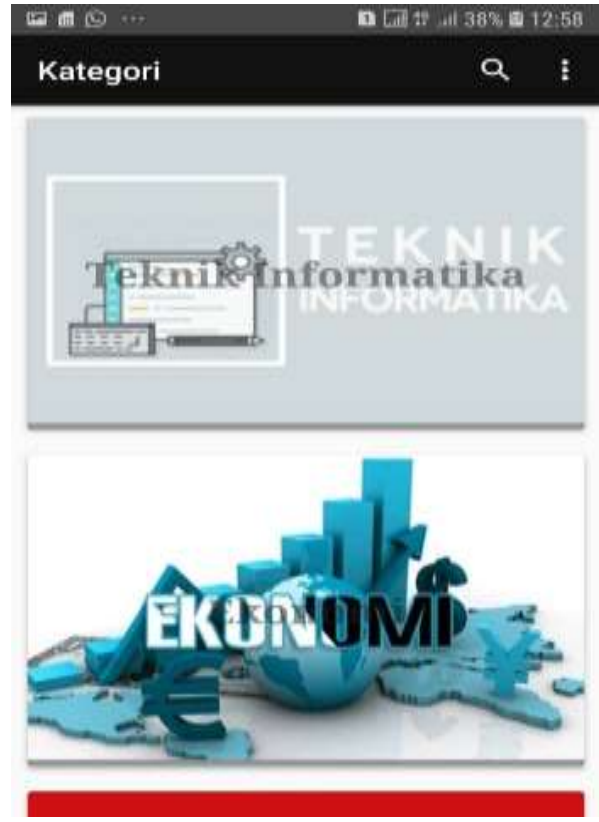

Gambar 7. Kategori Jurnal

3. Halaman Aplikasi Hasil Jurnal

Halaman ini menampilkan hasil jurnal dari tiap-tiap kategori jurnal yang dipilih. Detail yang dita mpilkan dari hasil jurnal adalah berupa jurnal tersebut. Gambar tampilan hasil jurnal ditunjukkan dapat dilihat pada Gambar 8.

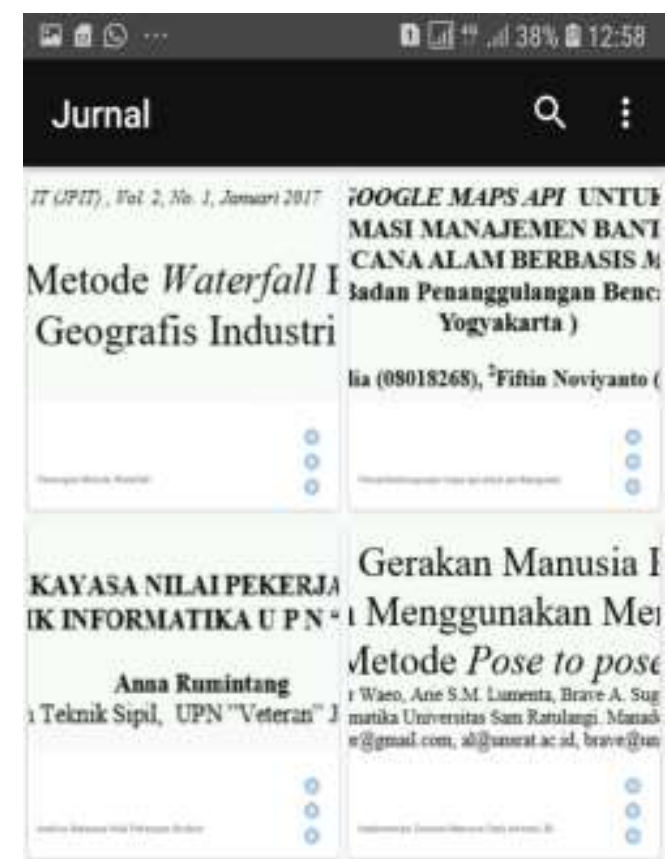

Gambar 8. Tampilan Hasil Jurnal

4. Halaman Aplikasi Lihat Jurnal

Pada halaman ini ditampilkan lihat jurnal. Setelah dipilih akan menampilkan lihat jurnal yang terkait. Gambar tampilan halaman lihat jurnal dapat dilihat pada Gambar 9. 


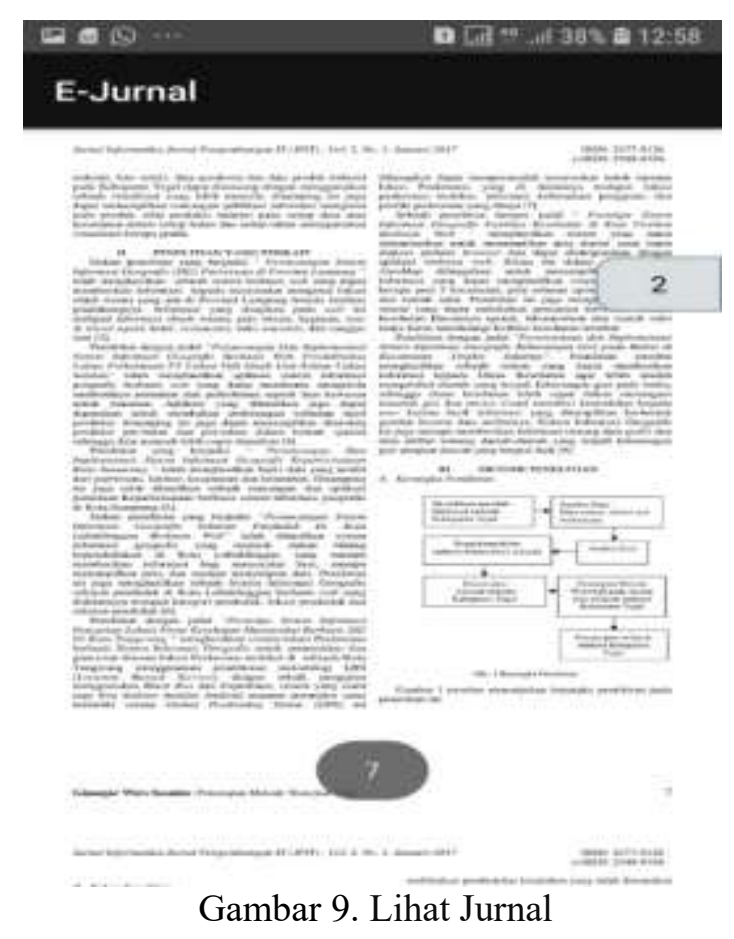

5. Halaman Profil Aplikasi

Pada halaman ini menampilkan informasi tentang profil pembuat aplikasi. Gambar tampilan halaman tentang aplikasi dapat dilihat pada Gambar 10.
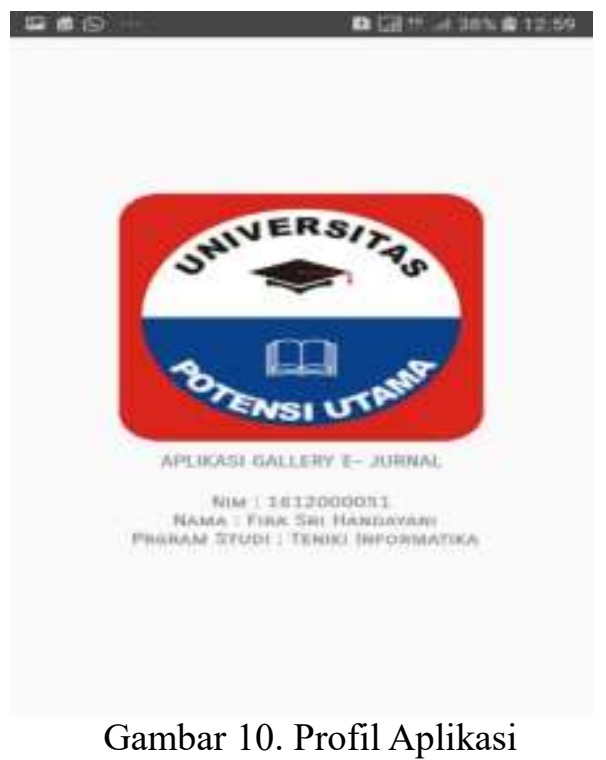

\subsection{Uji Coba Hasil}

Hasil uji coba merupakan pengujian black box terhadap aplikasi untuk mengetahui hasil dari perancangan antar muka aplikasi saat dijalankan pada smartphone android. Hasil pengujian dapat dilihat pada Tabel 1. 
Tabel 1. Uji Coba Hasil

\begin{tabular}{|c|c|c|c|c|}
\hline $\begin{array}{c}\text { No } \\
\text {. }\end{array}$ & $\begin{array}{l}\text { Skenario } \\
\text { Pengujian }\end{array}$ & Hasil yang diharapkan & Hasil Pengujian & Kesimpulan \\
\hline 1. & $\begin{array}{l}\text { Menjalankan } \\
\text { aplikasi admin }\end{array}$ & $\begin{array}{c}\text { Aplikasi dapat di dijalankan } \\
\text { pada web browser }\end{array}$ & $\begin{array}{l}\text { Aplikasi berjalan dengan } \\
\text { baik pada web browser }\end{array}$ & Valid \\
\hline 2. & $\begin{array}{l}\text { Menjalankan } \\
\text { aplikasi } \text { user }\end{array}$ & $\begin{array}{l}\text { Aplikasi dapat di install pada } \\
\text { smartphone android dan dapat } \\
\text { dijalankan sesuai } \\
\text { perancangannya }\end{array}$ & $\begin{array}{c}\text { Aplikasi berjalan dengan } \\
\text { baik pada perangkat } \\
\text { smartphone android }\end{array}$ & Valid \\
\hline 3. & $\begin{array}{l}\text { Menu Halaman } \\
\text { Utama }\end{array}$ & $\begin{array}{c}\text { Aplikasi ini dapat } \\
\text { menampilkan daftar Jurnal }\end{array}$ & $\begin{array}{c}\text { Aplikasi menampilkan } \\
\text { daftar Jurnal }\end{array}$ & Valid \\
\hline 4. & E-Jurnal & $\begin{array}{l}\text { Aplikasi dapat digunakan } \\
\text { sebagai sistem e-jurnal }\end{array}$ & $\begin{array}{l}\text { Aplikasi dapat melakukan } \\
\text { e-jurnal pada perangkat } \\
\text { smartphone android. }\end{array}$ & Valid \\
\hline 5. & $\begin{array}{l}\text { Hasil Aplikasi } \\
\text { Jurnal }\end{array}$ & $\begin{array}{l}\text { Aplikasi dapat Menampilkan } \\
\text { jurnal - jurnal. }\end{array}$ & $\begin{array}{l}\text { Aplikasi menampilkan } \\
\text { Jurnal - jurnal pada aplikasi } \\
\text { admin dan aplikasi android. }\end{array}$ & Valid \\
\hline
\end{tabular}

\section{KESIMPULAN}

Berdasarkan hasil analisa yang dilakukan oleh penulis, pada perancangan apliaksi e-jurnal pencarian sebuah jurnal. Dari keseluruhan hasil pengujian yang dilakukan dapat disimpulkan beberapa hal sebagai berikut:

1. Aplikasi e-jurnal pencarian jurnal berjalan dengan baik pada perangkat smartphone android.

2. Aplikasi dapat mempermudah mahasiswa/mahasiswi dalam proses pencarian jurnal.

3. Aplikasi dapat berjalan secara online dan terhubung dengan baik.

\section{SARAN}

Dalam mengerjakan perancangan aplikasi e-jurnal pencarian sebuah jurnal berbasis android, terdapat beberapa kendala yang dihadapi penulis Maka penulis akan menyampaikan beberapa saran yang diharapkan pembaca dapat memahami dan mengembangkan penelitian ini. Adapun saran - saran tersebut adalah :

1. Diharapkan aplikasi ini dapat dikembangkan lebih lanjut, agar yang disajikan dapat lebih jelas, lebih lengkap, lebih banyak agar menjadi suatu e-jurnal secara lengkap.

2. Diharapkan kedepannya peran aktif admin untuk memperbaharui (update) informasi sebuah jurnal.

3. Perlu adanya tingkat keamanan yang lebih tinggi pada aplikasi admin agar tidak mudah di bobol oleh pihak-pihak yang tidak bertanggung jawab.

\section{DAFTAR PUSTAKA}

[1] Batubara, H. H. (2018). Pengembangan Media Pembelajaran Matematika berbasis Android untuk Siswa SD/MI. Muallimuna: Jurnal Madrasah Ibtidaiyah, 3(1), 12-27.

[2] Setyadi, D. (2017). Pengembangan mobile learning berbasis android sebagai sarana berlatih mengerjakan soal matematika. Satya Widya, 33(2), 87-92.

[3] Athoillah, M., \& Irawan, M. I. (2013). Perancangan sistem informasi mobile berbasis Android untuk kontrol persediaan barang di gudang. Jurnal Sains dan Seni Pomits, 1(1), 16.

[4] Surahman, S., \& Setiawan, E. B. (2017). Aplikasi Mobile Driver Online Berbasis Android Untuk Perusahaan Rental Kendaraan. Ultima InfoSys: Jurnal Ilmu Sistem Informasi, 8(1), 3542.

[5] Rulloh, A., Mahmudah, D. E., \& Kabetta, H. (2017). Implementasi REST API pada Aplikasi Panduan Kepaskibraan Berbasis Android. Teknikom: Teknologi Informasi, Ilmu Komputer dan Manajemen, 1(2), 85-89. 
[6] Putra, G. Z., Mahendra, N. B., Kusuma, M. B. I., \& Satriawan, G. A. (2019). Aplikasi Deteksi Gempa Secara Realtime Berbasis Mobile di Indonesia. J-INTECH, 7(02), 135-139.

[7] Sibagariang, S. (2016). Web Service Rest Pada Perpustakaan Berbasis Android. Jurnal Mahajana Informasi, 1(2), 8-11.

[8] Yusrizal, Y., Dawood, R., \& Roslidar, R. (2017). Rancang Bangun Layanan Web (Web Service) Untuk Aplikasi Rekam Medis Praktik Pribadi Dokter. Jurnal Karya Ilmiah Teknik Elektro, 2(1).

[9] Aziz, K. E., Dardiri, M. H., \& Yaqin, M. A. (2020). Pengembangan Web Service Sistem Informasi Sekolah. Jurasik (Jurnal Riset Sistem Informasi dan Teknik Informatika), 5(1), 154-165.

[10] Lanvino, F., Sukhoco, A. Y., \& Aliman, W. (2020). PERANCANGAN SISTEM INFORMASI PENCATATAN KEHADIRAN MAHASISWA DENGAN TEKNOLOGI QR CODE. Antivirus: Jurnal Ilmiah Teknik Informatika, 14(2), 125-141.

[11] Fauzi, R. M., \& Nurpandi, F. (2020). Perancangan Dan Pembangunan AplikasiRekrutmen Asisten Laboratorium Berbasis Mobile. Media Jurnal Informatika, 11(2), 15-25.

[12] Sadikin, M., \& Gunawan, H. (2020). Peningkatan Sistem Seleksi Ujian Saring Masuk dengan Metode Linear Congruent Method Berbasis Mobile (Studi Kasus: Universitas Potensi Utama). Jurnal Mahasiswa Fakultas Teknik dan Ilmu Komputer, 1(1), 1101-1112.

[13] Haryanto, E. V., Nataperdana, A., \& Kurniawan, H. (2017, October). PERANCANGAN ALAT STEMPEL OTOMATIS LEMBAR JAWABAN STMIK POTENSI UTAMA. In Seminar Nasional Informatika (SNIf) (Vol. 1, No. 1, pp. 173-177).

[14] Sitepu, A. I. B., \& Tanjung, D. Y. H. (2020). Rancang Bangun Aplikasi Pemesanan dan Penjualan Berbasis Web dan Android pada Toko YT. Wall Interior. Jurnal Mahasiswa Fakultas Teknik dan Ilmu Komputer, 1(1), 816-828. 